Binghamton University

The Open Repository @ Binghamton (The ORB)

2015

\title{
A Review of Locomotion Systems for Capsule Endoscopy
}

Lejie Liu,

Binghamton University--SUNY

Shahrzad Towfighian

Binghamton University--SUNY, stowfigh@binghamton.edu

Amine Hila

Follow this and additional works at: https://orb.binghamton.edu/mechanical_fac

Part of the Mechanical Engineering Commons

\section{Recommended Citation}

Liu, Lejie; Towfighian, Shahrzad; and Hila, Amine, "A Review of Locomotion Systems for Capsule Endoscopy" (2015). Mechanical Engineering Faculty Scholarship. 8.

https://orb.binghamton.edu/mechanical_fac/8

This Article is brought to you for free and open access by the Mechanical Engineering at The Open Repository @ Binghamton (The ORB). It has been accepted for inclusion in Mechanical Engineering Faculty Scholarship by an authorized administrator of The Open Repository @ Binghamton (The ORB). For more information, please contact ORB@binghamton.edu. 


\title{
A REVIEW OF LOCOMOTION SYSTEMS FOR CAPSULE ENDOSCOPY
}

\author{
Lejie Liu, Shahrzad Towfighian, and Amine Hila
}

Methodological Review

\begin{abstract}
Wireless capsule endoscopy for gastrointestinal (GI) tract is a modern technology that has the potential to replace conventional endoscopy techniques. Capsule endoscopy is a pillshaped device embedded with a camera, a coin battery and a data transfer. Without a locomotion system, this capsule endoscopy can only passively travel inside the GI tract via natural peristalsis, thus causing several disadvantages such as inability to control and stop, and risk of capsule retention. Therefore, a locomotion system needs to be added to optimize the current capsule endoscopy. This review summarizes the state-of-the-art locomotion methods along with the desired locomotion features such as size, speed, power and temperature and compares properties of different methods. In addition, properties and motility mechanisms of the GI tract are described. The main purpose of this review is to understand the features of GI tract and diverse locomotion methods in order to create a future capsule endoscopy compatible with GI tract properties.
\end{abstract}

\section{INTRODUCTION}

C ONVENTIONAL (flexible) endoscopy has been widely used to identify and monitor diseases in gastrointestinal (GI) tract such as crohn's disease, celiac disease, smallintestine tumors, colorectal cancer etc [1]-[4]. However, flexible endoscopy can have complications and may cause severe pain to patients. In addition, it is hard to monitor some area of GI tract including the largest part of the small bowel [5]. Furthermore, conventional endoscopes need to be operated by professional endoscopists which require a long training time [6]. Therefore, wireless capsule endoscopy was invented, but its functionality is still under investigation. Inchoate capsule endoscopy is basically a pill-shaped device embedding a camera with several LEDs, a coin battery and a data transfer. Once the patient swallows the capsular device, it moves passively through the GI tract via peristalsis. Meanwhile, it starts to take photographs with a constant frequency and transfers the pictures to an external data receiver. The first wireless capsule endoscopy was invented 14 years ago by Swain and Given Imaging (Yoqneam, Israel) [7]. This device consists of several components: an optical dome, a lens holder, a short focal length lens, four LEDs, a complementary metal

Lejie Liu is with the Department of Mechanical Engineering, SUNY Binghamton, Binghamton, NY, 13902 USA (e-mail: 1liu34@binghamton.edu)

Shahrzad Towfighian is with the Department of Mechanical Engineering, SUNY Binghamton, Binghamton, NY, 13902 USA, (e-mail: stowfigh@binghamton.edu) Address all correspondence to this author

Amine Hila is with the Upstate Medical School and UHS hospitals, NY, 13903 USA (e-mail: hilagi@hotmail.com) oxide semiconductor image sensor, two silver oxide batteries, an ASIC radio-frequency transmitter, and external receiving antenna [8].

Several commercial capsule endoscopies developed by different companies became available after 2000 : EndoCapsule (Olympus, Japan) [9], MiRo capsule (IntroMedic, Korea) [10], and OMOM capsule (Jinshan Science and Technology, China) [11]. In the meantime, second-generation capsule endoscopy named CCE-2 (colon capsule endoscopy) was manufactured and commercially applied in Europe [12]. Compared to the first-generation capsule, the CCE-2 capsule has two cameras with wider view angle, which can provide 172 degrees per camera to observe the panorama of the colon wall. When the frame rate is properly adjusted, the CCE-2 capsular device can last for at least 10 hours.

Although the passive capsule endoscopy technology is in the mature stages of development, many inevitable drawbacks limit its application. For example, it cannot stop at a certain position for diagnostic purposes, and it may cause capsule retention (where a capsule stays in the GI tract for at least 2 weeks) and other complications [13]. Therefore, adding a locomotion system would optimize current capsule endoscopy capabilities.

Several research groups have made great efforts to develop different active capsule endoscopies [14]-[19]. However, because of the complexity of the GI tract and power consumption limitation, automatic capsule endoscopy is still constrained at laboratory level. Therefore, understanding the mechanical properties of the GI tract combined with consideration of requirements of active capsule endoscopy are necessary prerequisites to build a practical robotic capsule endoscopy.

The rest of the paper is organized as follows. Section 2 will discuss the properties and motility of the GI tract and illustrate how these properties affect capsule endoscopy. Section 3 presents the diverse active capsule endoscopies with analysis and assessment. It will end with a view of the next generation capsule endoscopy.

\section{GASTROINTESTINAL TRACT PROPERTIES}

\section{A. Fundamental Knowledge}

The gastrointestinal tract includes four organs: esophagus, stomach, small intestine, and colon (Fig. 1). The esophagus is about $25-30 \mathrm{~cm}$ in length and $2-3 \mathrm{~cm}$ in diameter. The width of the stomach is $25 \mathrm{~cm}$ and the volume is 0.1-4 liters to accommodate food [20]. The major areas that the capsule 
endoscopy moves along are the small intestine and the large intestine.

The small intestine consists of three structural parts: duodenum $(20-25 \mathrm{~cm} \times \phi 3-4 \mathrm{~cm})$, jejunum $(2.4 \mathrm{~m} \times \phi 2-3 \mathrm{~cm})$ and ileum $(2-4 \mathrm{~m} \times \phi 1.5-2.5 \mathrm{~cm})$ as shown in Fig. 1 .

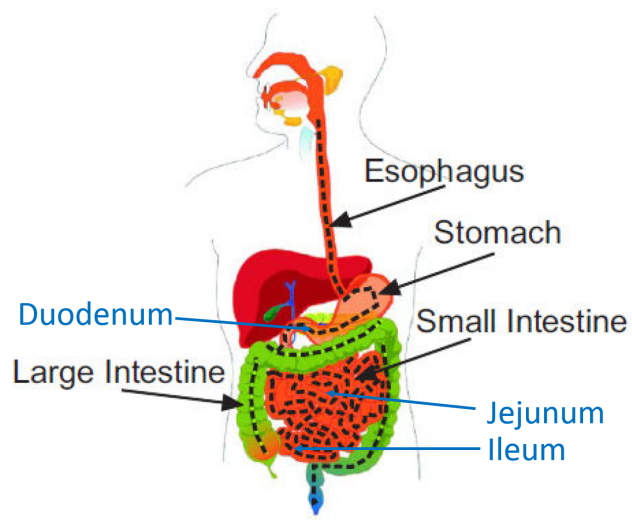

Fig. 1: Components of gastrointestinal tract (Reprinted with permission. Copyright 2011, IEEE [21])

The duodenum and jejunum play major parts in digestion and absorption. The ileum is known as indigested and unabsorbed region [22]. The inner structure of the small intestine is the most complex, when compared with the other components of the GI tract. The plicate surface (mucosal folds) of the intraluminal wall is covered with a layer of villi lying on the lamina propria [23]. This typical viscoelastic tissue is known as mucosa (Fig. 2), which continually secretes a lubricating mucus layer for protection purpose. According to Valdastri et al. [24], the thickness of the mucus layer is around 2 $\mathrm{mm}$. Beneath the mucosa (and submucosa) is the smooth muscle layer that can be divided into circular muscle layer and longitudinal muscle layer, as shown in Fig. 2.

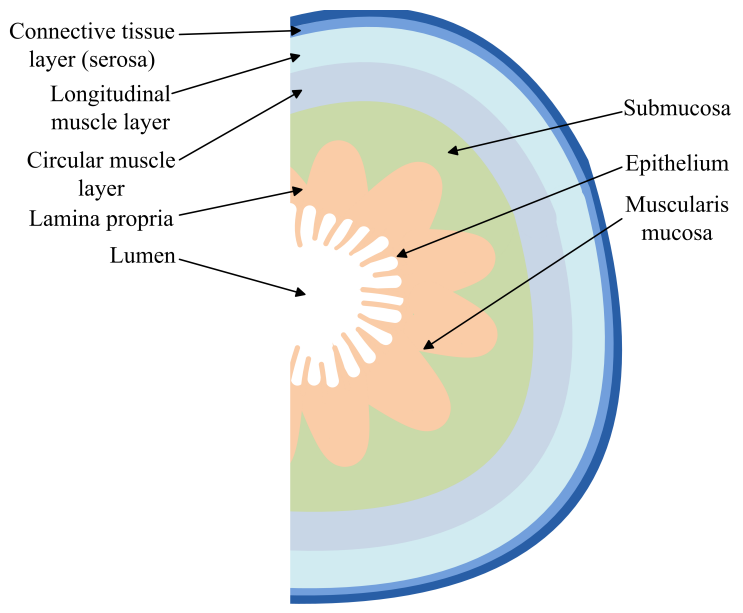

Fig. 2: Layers of the GI tract (Adapted from [23])

In general, the functions of the smooth muscle distributed in the entire GI tract can be divided into two types, phasic and tonic. The phasic muscle dominates the short period contractions commonly engendered in the stomach, small and large intestine, whereas the tonic muscle controls long period contractions that can last minutes or hours generally occurring in the ileocecal sphincter and internal anal sphincter [23]. The small intestine digests and propels food based on the smooth muscle, and consists two basic motions: segmentation and peristaltic.

Segmentation is defined as alternate contractions of different rings of circular muscle as shown in Fig. 3, which is used in the small intestine to divide the chyme into small particles. Particles then are mixed with digestive juices for better absorption. The estimation frequency of segmentation is about $12 / \mathrm{min}$ at the distal of duodenum and $8 / \mathrm{min}$ in the ileum [25], [26]. The frequency of segmentation varies greatly during different periods. It may be very slow in fasting, and becomes frequent after feeding. Several studies and observations prove that segmental contractions move chyme slowly in the aboral direction [27].

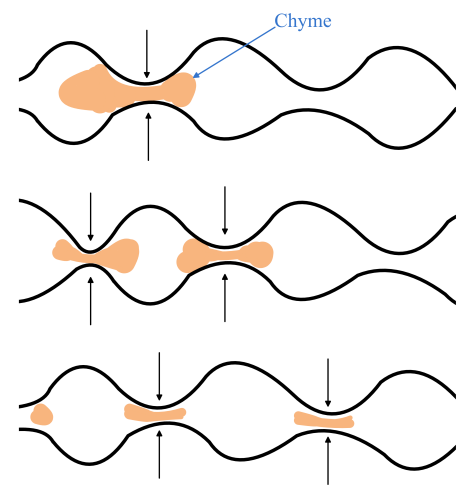

Fig. 3: Segmentation motion of GI tract (Adapted from [23])

Unlike segmentation, peristalsis is known as the sequential contraction and relaxation of contiguous rings of smooth muscle, as shown in Fig. 4. A wave of peristalsis consist of two basic types. Basic peristalsis waves move only $10 \mathrm{~cm}$ along the small intestine before vanishing, whereas "peristaltic rushes" occur occasionally and travel along the entire bowel. The common velocity of peristalsis is about $1-2 \mathrm{~cm}$ per minute.

The large intestine is a tube $150 \mathrm{~cm}$ in length and $6 \mathrm{~cm}$ in diameter, and consists of six structural parts: the caecum, the ascending colon, the transverse colon, the descending colon, the sigmoid colon, and the rectum, as shown in Fig. 5. The inner structure of the large intestine is similar to the small intestine but it has no villi because its main function is not to absorb chyme but to store feces. The motility of the large intestine is similar to the small intestine. The rectum commonly contracts more frequently than the more proximal parts.

In addition to GI tract motility, the resistance and pressure exerted by the intestinal wall are commonly concerned when a capsule endoscopy experiences inside the GI tract (especially within the intestinal area), which will be discussed next. 


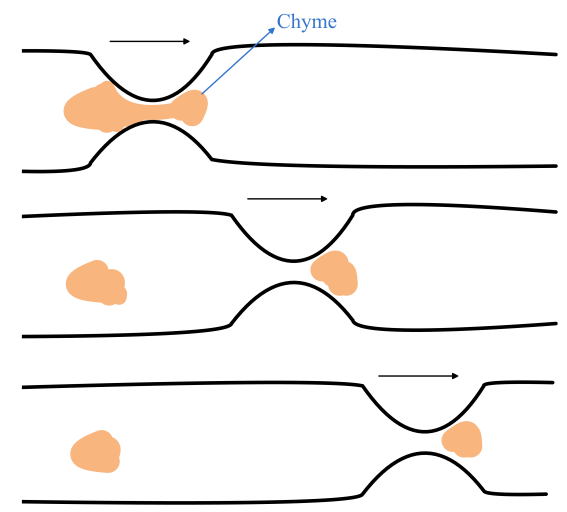

Fig. 4: Peristalsis motion of GI tract (Adapted from [23])

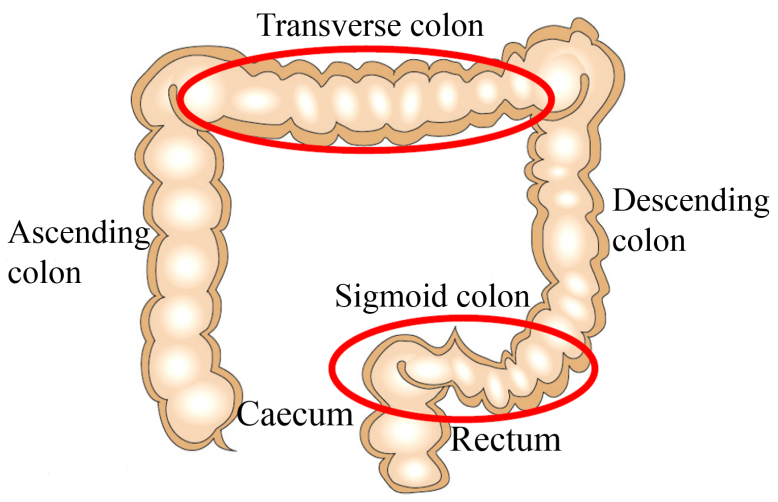

Fig. 5: Components of large intestine (Reprinted with permission. Copyright 2009, IEEE [28])

\section{B. Transit Time and Pressure}

For designing a capsule endoscopy, transit time during peristalsis and hoop stress during segmentation are important factors. Fynne et al. [29] presented a magnet tracking system to measure the transit time in the stomach and small intestine. The experimental results showed that gastric transit time is about $35.5 \mathrm{~min}$ and the small intestinal transit time is 260.5 min. They also reported that peristalsis velocity of the small intestine is $2.2 \mathrm{~cm} / \mathrm{min}$ during fasting period and $2.3 \mathrm{~cm} / \mathrm{min}$ in postprandial period, and the gastric contraction frequency is $2.85 \pm 0.29 / \mathrm{min}$.

Arman et al. [30] reported the hoop pressure measured by a telemetry capsule. However, the in vitro test can only measure the hoop stress caused by small intestine extension (when the diameter of capsule is larger than the diameter of the small intestine). It cannot measure the contracting stress. Based on their study, the hoop stress generated by intestinal extension is about $2.47 \mathrm{KPa}$. Zhang et al. [31] Accomplished an in vivo experiment in the colon using a similar approach. They reported that contraction hoop stress is about $62 \mathrm{KPa}$ during fasting and about $121 \mathrm{KPa}$ after meals. They also found that transit time in colon is about $30 \mathrm{~min}$. Hoop strss is an important design factor for capsule endoscope, since the material should be strong enough to resist the applied stresses.

\section{Resistance}

Active capsule endoscopy should overcome the resistance acted on it by the luminal wall in order to successfully navigate along the GI tract. Jang et al. [32], [33] proposed an experimental study on frictional force and viscoelastic properties of the small intestine. In addition to normal load and friction coefficient, they mentioned that frictional resistance is related to two components: the surface geometry and moving speed. First, a cylindrical shape of the capsule experiences the least resistance, and reducing the contact surface area decreases resistance, but the influence is not significant. Surface geometry effect on frictional proportion was also studied by Wang et al. [34]. They pointed out that the diameter of the capsule is more important than the capsule length to affect resistance. Second, higher velocity of the capsule endoscopy generates higher resistance, and it can be explained by considering the stress relaxation property of the body tissue. Therefore, a five-element model as shown in Fig. 6 was built to define the hoop stress acting on the capsule in order to predict the resistance. Furthermore, they established both an analytical solution and a FE model to predict the resistance, which is made of three components: friction force generated by capsular weight, friction force generated by viscoelastic deformation, and the resistance related to the contraction pressure of the intestinal wall [35]. According to their study, the average frictional resistance between capsule and intestinal wall is 20$50 \mathrm{mN}$ under a velocity of $0.5 \mathrm{~mm} / \mathrm{s}$.

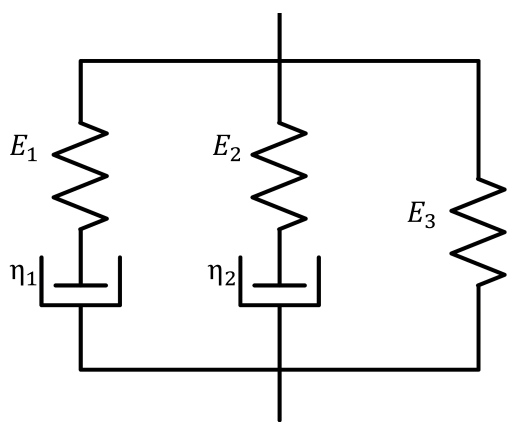

Fig. 6: Five-element model for intestinal tissue (Adapted from [33])

\section{LOCOMOTION METHODS}

When considering an active capsule endoscopy, the key to propel the capsule is the actuator. Diverse locomotion methods can be roughly classified into three types depending on the use of the actuator: (1) Internal locomotion method, namely, the actuator is embedded on the capsule endoscopy inside the patient's body; (2) External locomotion method, namely, the actuator is outside the patient's body; (3) Other methods which are different from the internal and external methods. 


\section{A. Fundamental Properties of Locomotion System}

In order for the locomotion systems to have satisfactory performance, certain properties are desired. First, the speed should be in the range of $15 \mathrm{~cm} / \mathrm{min}$ to be compatible with GI tract motion and to allow suitable picturing capability. Second, the power requirement should be minimized and when possible an energy support system be offered. Third, the size of the capsule should be no larger than $1.5 \mathrm{~cm}$ in diameter and 3 $\mathrm{cm}$ in length, otherwise it is uncomfortable for the patient to swallow. Fourth, the temperature of the capsule cannot go beyond $43{ }^{\circ} \mathrm{C}$ to be safe in contact with the tissue. Fifth, the locomotion system should make no damage to the body tissues. Current locomotion systems are described next and a summary of each method is given at the end of each category comparing their properties.

\section{B. Internal Locomotion Method}

1) Friction Force Based Method: Most researchers prefer the friction force based method, because its simple mechanism leads to a concise structure of the active capsule endoscopy. It can be subdivided into specific mechanisms as follows.

a) Inchworm-like mechanism: The inchworm-like mechanism for capsule endoscopy requires three basic functions: anchoring, elongating, and contracting, done by actuators made of shape memory alloys (SMA). A variety of stopping mechanisms have been applied including the microfibrillar adhesives, proposed by Cheung et al. [36], [37]. They adopted beetle inspired micro-patterned adhesives fabricated from polydimethylsiloxane (PDMS) to generate the attraction force, which combines van der Waals forces and liquid adhesive forces, between the capsule and intestine wall. A prototype capsule consisting of SMA wire, compression spring and six legs with adhesive pads on the tips were built as shown in Fig. 7. The capsule can move forward and backward due to the contracting and elongating of the capsule body by sequentially actuating and cooling down the SMA wire.

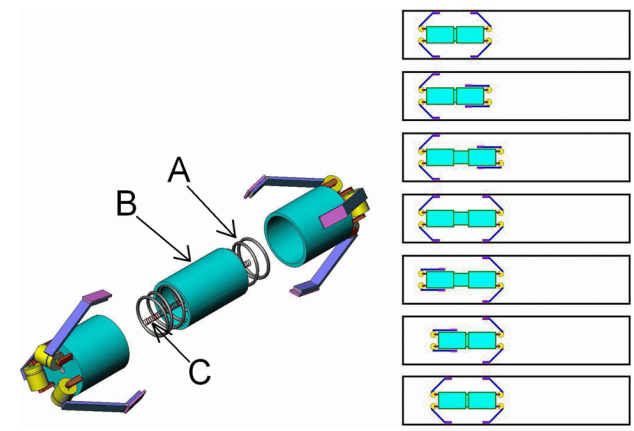

Fig. 7: Locomotion diagram of inchworm-like mechanism (Reprinted with permission. Copyright 2006, IEEE [37])

An inchworm-like endoscopic capsule was also presented by Hosokawa et al. [38], [39] applying SMA wire actuator. The mechanism of stretching and contracting the capsule body is practically the same as the above prototype capsule. However, the stopping mechanism is based on suction cups. As shown in Fig. 8a, the suction cup can stick to or remove from the intestine wall by actuating or cooling down the SMA actuator installed in the suction cup. As shown in Fig. 8b, this attachment method can prevent the free segment from slipping in the opposite direction when the capsule moves.
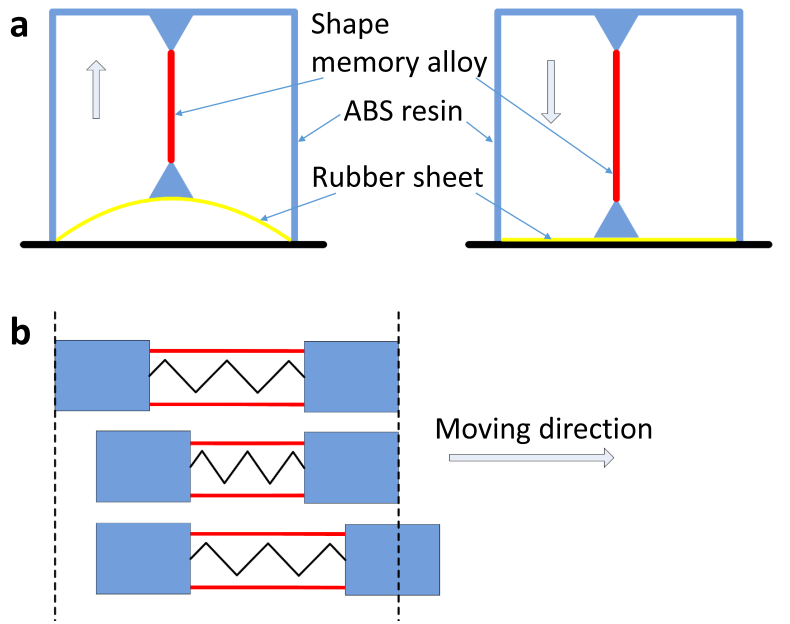

Fig. 8: Locomotion mechanism of suction cup based capsule endoscopy (Adapted from [38]) a. suction cup principle, b. moving principle

Using SMA wires, another two different inchworm-like capsules were developed by Kim et al. [17], [40]-[43]. SMA spring and piezo actuator were used to generate the propelling force, in the meantime, micro-needle and pitch depth of capsule body were applied for clamping purpose respectively. Fig. 9 shows the basic principle of SMA spring combining with the needle clampers. When the SMA spring actuated by electrical heating, the rear segment moves forward whereas the front part stays at the fixed point due to the needle pad. After the SMA spring cools down, the bias spring elongates because of the elastic potential energy to push the front segment forward. The reason the rear and front segments cannot slip along the opposite direction is that all the needles on the pad are assembled facing backward direction so that they can prevent the two segments from slipping backward.

As an alternative actuation method, piezo actuators were also used to move the capsule [42]. The actuators were driven by saw tooth pulse voltage. The outer body of the capsule was covered by several pitch depth for stopping purposes as shown in Fig. 10. The critical stroke is about $7 \mathrm{~mm}$ for the earthworm-like robotic capsule endoscopy.

Shape Memory Alloys (SMA): Since shape memory alloys are commonly adopted as actuators for the inchworm-like locomotion systems, it's necessary to understand the constitutive properties and to assess the applicability of SMAs for GI tract use. As its name suggests, shape memory alloys represent a peculiar type of materials which can return to their 


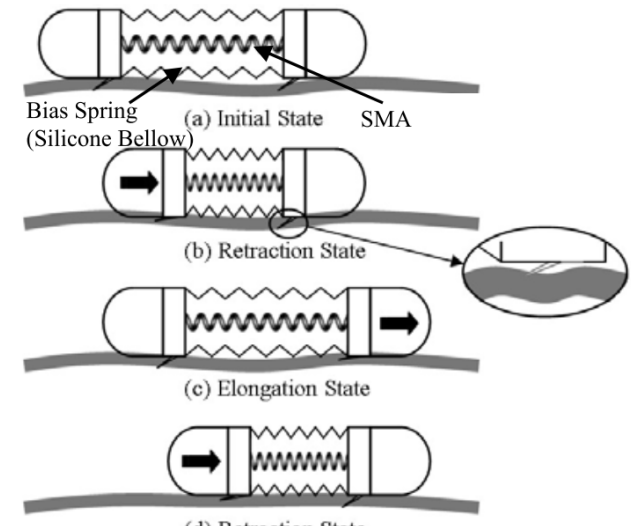

(d) Retraction State

Fig. 9: Moving cycle of needle based mechanism (Reprinted with permission. Copyright 2009, IEEE [40])

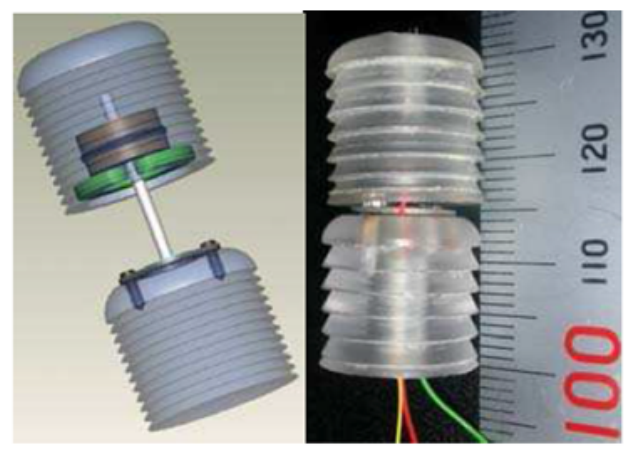

Fig. 10: Piezo actuator and pitch depth stopping mechanism (Reprinted with permission. Copyright 2005, IEEE [42])

original shape after deformation by simply changing the inner or circumambient temperature. The first application of SMAs occurred in 1969 by the Raychem Corporation who produced a Ni-Ti-based hydraulic coupling for the Grumman Corporation [44]. The major property of SMAs is the transformation between austenitic phase and martensitic phase [45]-[48]. As shown in Fig. 11, there are four transition phases: 1) $\mathrm{M}_{S}-$ martensite start (at this temperature, martensite layer starts to appear); 2) $\mathbf{M}_{F}$ - martensite finish (at this temperature, all material specimen completely transform into martensite phase); 3) $\mathrm{A}_{S}$ - austenite start (at this temperature, the austenite layer starts to appear); 4) $\mathrm{A}_{F}$ - austenite finish (at this temperature, all material specimen completely transforms into austenite phase). It's obvious that hysteresis exists between the heating and cooling cycles, and such hysteresis temperature varies due to the change in compositions of SMAs. The hysteresis temperature is about 30 to $50^{\circ} \mathrm{C}$ for titanium-nickel (TiNi) alloys, around 10 to $25^{\circ} \mathrm{C}$ for copper-zinc-aluminum $(\mathrm{CuZnAl})$ alloys, and 15 to $20^{\circ} \mathrm{C}$ for copper-aluminum-nickel (CuAlNi) alloys.

In order to be a practical actuator, an SMA should achieve

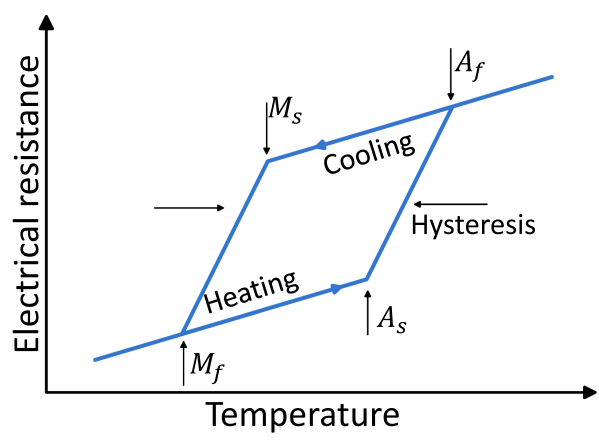

Fig. 11: Four transition phases (Adapted from [49])

the following goals.

- TWM Effect Requirement: Common actuators require SMAs to have a two way memory effect (TWM). Usually an SMA presents one-way effect, so a widely used method to obtain TWM ability is to combine the SMA with a bias component such as a bias spring.

- Enough Cycling Lifetime: Repeatedly increasing and decreasing temperature may cause material failure, so long cycling lifetime is desired.

- Appropriate actuator temperature range: Considering the thermal safety, the heating and cooling transformation temperature should not be higher than $43^{\circ} \mathrm{C}$ which is the thermal threshold for the GI tract [50], [51].

- Short hysteresis region: As mentioned above, each type of SMAs has its own hysteresis region. Minimum hysteresis region is necessary for actuator design. In addition, thermal safety of GI tract is another important reason to shorten the hysteresis region. Therefore, $\mathrm{TiNiCu}$ with a hysteresis lower than $3^{\circ} \mathrm{C}$ and an R-phase transition in TiNi alloys with a $1.5^{\circ} \mathrm{C}$ hysteresis region are best to be used as locomotion actuators. A summary of inchworm-like based locomotion system is given in Tab. 1.

\section{Summary}

According to the table, each inchworm-like capsule endoscopy has its own practical stop mechanism that allows endoscopists for in situ monitoring, and its unique locomotive function can easily accomplish both forth and back motion. However, SMAs based inchworm-like capsule endoscopies have several inevitable limitations: high power consumption in the range of 450-1700 $\mathrm{mW}$ and slow response. Moreover, heating SMAs causes conspicuous changes in temperature $\left(12^{\circ} \mathrm{C}\right.$ in 3 minutes [43]), which may damage the intestinal tissue. In terms of size, SMA and compression spring method [38] has a length $4 \mathrm{~cm}$ which exceeds the limit of $3 \mathrm{~cm}$ length as the desired length. In addition, the existence of the stoke of SMA springs limits the compactness of capsule endoscopies.

b) Paddle/legged based mechanism: Another prevalent locomotion method of friction force based mechanism is known as paddle based motion. As the name suggests, this type of locomotion mechanism is inspired by paddling a canoe: several paddles or legs embedded on the capsule endoscopy are driven 
by actuators to push backward against the luminal wall, and the capsule endoscopy can navigate forward due to the reaction force. Park et al. [52], [53] proposed a paddling-based capsule endoscopy shown as Fig. 12a.

$\mathbf{a}$
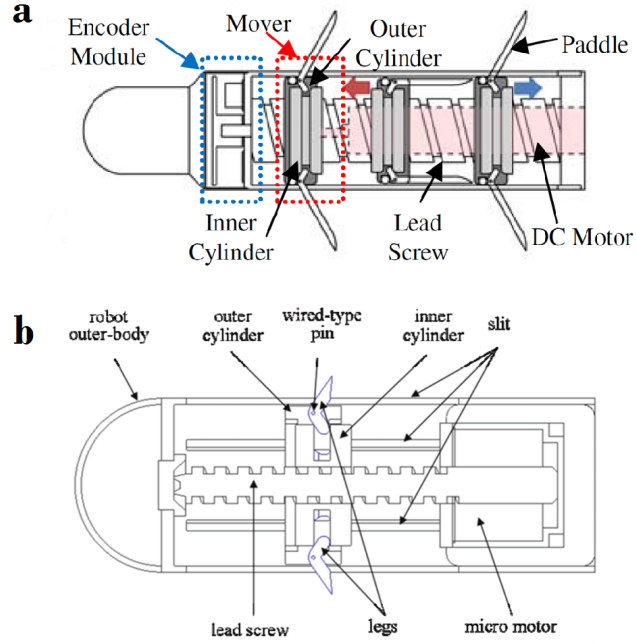

Fig. 12: Paddling-based capsule endoscopy a. Park et al. (Reprinted with permission. Copyright 2011, IEEE [53]), b. Yoon et al. (Reprinted with permission. Copyright 2007, IEEE [18])

A similar paddle based capsule endoscopy was presented by Yoon et al. [18] as shown in Fig. 12b. A DC motor was selected as the actuator and a lead screw was chosen to transform the rotation movement generated by the DC motor into linear motion. This linear motion could force the paddles to stretch or fold via the outer or inner cylinders (Fig. 13). In order to move forward, the lead screw actuated by the micro motor drives the outer cylinder forcing paddles to stretch, and then paddles clamp the GI tract surface. In the meantime, the lead screw pushes the paddles backward against the wall of GI tract, thus a reaction force drives the outer body to move forward. To return to the initial position, the DC motor reverses, and then the lead screw forces paddles to fold and disconnect from the surface of GI tract. This study indicated that the stroke of the microrobot should be no less than $5.6 \mathrm{~mm}$ to advance forward.

A 12-legged capsule endoscopy was also proposed by Quirini et al. [24] (Fig. 14). It is driven by a DC brushless motor designed to reduce individual foot forces [54]-[57]. This prototype had two DC motors with corresponding lead screws and nuts. Each motor controls one set of six super-elastic legs. The rear set of legs mainly generates the thrust force, while the front set of legs is in charge of anchoring the capsule when rear legs retract and helps the capsule move forward.

A ciliated cell based capsule endoscopy was proposed by Guo et al. [58] (Fig. 15a). The moving mechanism of the capsule is shown in Fig. 15b, where advancement occurs based on the different phases of fore and hind movement of the cilium. In fact, each of the two cilia just acts as a leg controlled by two-way SMA actuator which consists of

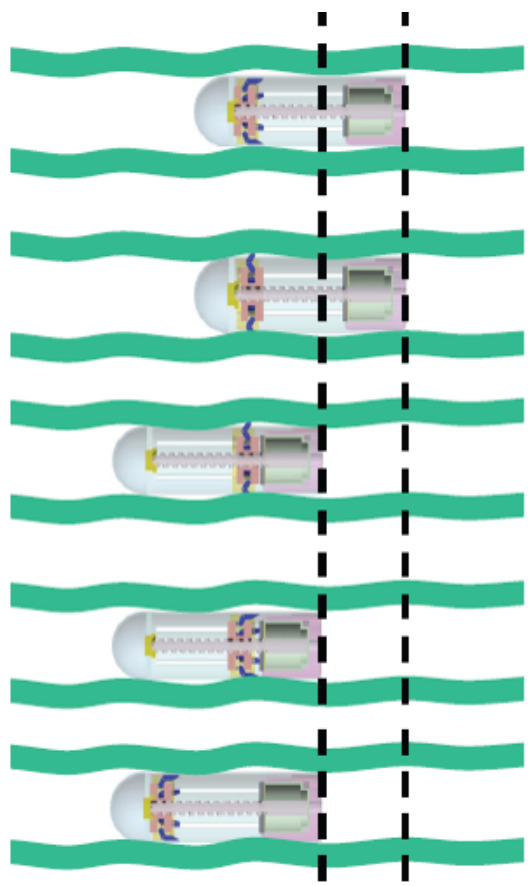

Fig. 13: Principle of moving forward for paddle based capsule (Reprinted with permission. Copyright 2007, IEEE [18])

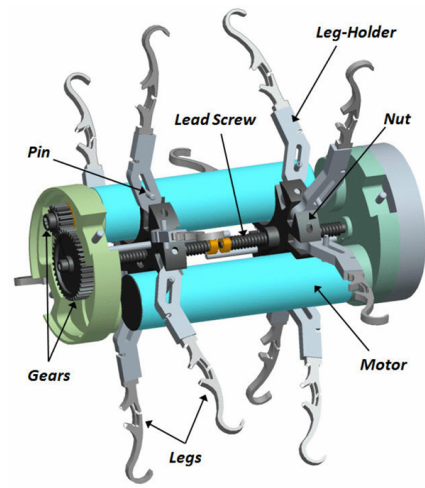

Fig. 14: 12 legged capsule endoscopy (Reprinted with permission. Copyright 2009, IEEE [24])

two parallel SMA springs. The springs are heated and cooled alternatively to move the capsule endoscopy up and forward. A brief extraction and comparison of paddle based locomotion method is organized in Tab. II.

\section{Summary}

Comparing Tab. II with the Tab. I, paddle based capsule endoscopies consume almost the same power, but generate significant larger velocities. Velocity reported by the two first methods in Tab. II, have larger velocity than desired velocity of $15 \mathrm{~cm} / \mathrm{min}$, which may not allow enough time for picturing folds inside GI tract. Due to the properties of 
TABLE I: Summary of inchworm-like capsule endoscopies

\begin{tabular}{|c|c|c|c|c|c|}
\hline Group & Prototype & Actuator & Size & Velocity & $\begin{array}{c}\text { Estimated power } \\
\text { consumption(During } \\
\text { heating period) }\end{array}$ \\
\hline Cheung et al. [36] & & SMA wire and spring & $\phi 10 \times 22 \mathrm{~mm}$ & $40 \mathrm{~mm} / \mathrm{min}$ & $1692 \mathrm{~mW}$ \\
\hline $\begin{array}{c}\text { Hosokawa et al. } \\
\text { [39] }\end{array}$ & & $\begin{array}{c}\text { SMA and } \\
\text { compression spring }\end{array}$ & $\begin{array}{c}48(\mathrm{~L}) \times 16(\mathrm{~W}) \\
\times 11(\mathrm{H}) \mathrm{mm}\end{array}$ & $9.6 \mathrm{~mm} / \mathrm{min}$ & $450 \mathrm{~mW}$ \\
\hline Kim et al. [43] & 1 & SMA spring & $\phi 13 \times 33 \mathrm{~mm}$ & $\begin{array}{c}\text { Theoretical: } 25.5 \\
\mathrm{~mm} / \mathrm{min} \text { Use battery: } 10 \\
\mathrm{~mm} / \mathrm{min}\end{array}$ & $600 \mathrm{~mW}$ \\
\hline
\end{tabular}

TABLE II: Summary of paddle/legged based capsule endoscopies

\begin{tabular}{|c|c|c|c|c|c|}
\hline Group & Prototype & Actuator & Size & Velocity & Estimated power consumption \\
\hline Park et al. [53] & & DC motor & $\phi 15 \times 43 \mathrm{~mm}$ & $\begin{array}{l}600 \mathrm{~mm} / \mathrm{min} \text { (in vitro } \\
\text { test) } 170 \mathrm{~mm} / \mathrm{min} \text { (in } \\
\text { vivo test) }\end{array}$ & $\begin{array}{c}600 \mathrm{~mW} \text { (without external } \\
\text { loads) } 1200 \mathrm{~mW} \text { (with } \\
\text { external loads) }\end{array}$ \\
\hline Yoon et al. [18] & & DC motor & $\phi 13 \times 30 \mathrm{~mm}$ & $286 \mathrm{~mm} / \mathrm{min}$ & Not given \\
\hline Quirini et al. [24] & & DC motor & $\phi 11 \times 25 \mathrm{~mm}$ & $50 \mathrm{~mm} / \mathrm{min}$ & $430 \mathrm{~mW}$ \\
\hline
\end{tabular}

DC motor and lead screw, paddle based capsule endoscopies cannot navigate backwards along the lumen. Also, this type of capsule cannot stop at a fixed point. Another limitation of this locomotion mechanism is the inevitable risk of tissue damage and capsule retention because of the sharp paddles or legs. Therefore, Quirini et al. [24] have optimized their prototype by adopting a round-shape for the tip of the leg and utilized stronger material for the legs.

c) Crawler mobility mechanism: The last type of friction force based mechanism is called crawler mobility which imitates a car or a tank to advance along the GI tract. Sliker et al. [16], [22], [59] first proposed such preliminary capsule endoscopy driven by a DC micromotor. The DC motor leads a planetary gearbox to drive a worm set. The shaft of the gearbox is connected with a stainless steel worm which meshes several worm gears. The protruded worm gears act as wheels to propel the whole capsule endoscopy to navigate forward. Since the first crawler capsular endoscopy is too large to be swallowed by a patient, several subsequent versions have been designed. The final version has six wheels generating a velocity of $600 \mathrm{~mm} / \mathrm{min}$. The size is about 35 $\mathrm{mm}$ in length and 15 in diameter, and the power consumption is about $200 \mathrm{~mW}$ in in-vitro testing. They adopted PDMS as the adhesive tread on the wheels to increase the contact friction traction. Furthermore, they proved that such PDMS tread allowed enough drawbar forces to propel the capsule endoscopy via in-vitro test. Compared with the former two locomotion systems, this locomotion type has faster speed and less power consumption, but its absence of anchoring function and inability of moving backwards are the main drawbacks for clinical operation.

2) Hydrodynamic Force Based Method: Hydrodynamic force based mechanism is widely employed for designing and fabricating swimming robots, therefore, some research groups 


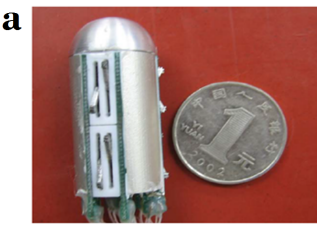

b

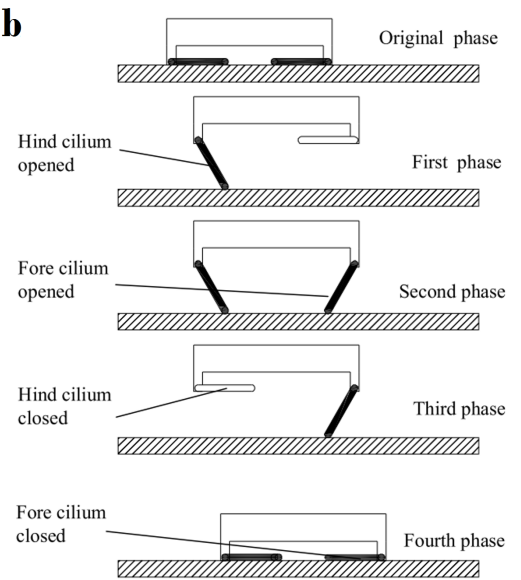

Fig. 15: Ciliated cell based capsule endoscopy (Reprinted with permission. Copyright 2006, IEEE [58]) a. ciliated cell based capsule endoscope, b. advance gait

adopted this simple mechanism for active capsule endoscopy. Chen et al. [60] made efforts for a swimming robotic capsule endoscopy composed of a spiral body and a steering head as shown in Fig. 16. The motility of this prototype capsule endoscopy can be divided into two modes: straight movement mode and steering mode. A DC motor was selected as the actuator for the straight motility. When the motor spins, the spiral body is forced to rotate simultaneously. When the spiral outer surface pushes mucus backward with reaction force, the capsule moves forward. In order to move backward, the DC motor is reversed.

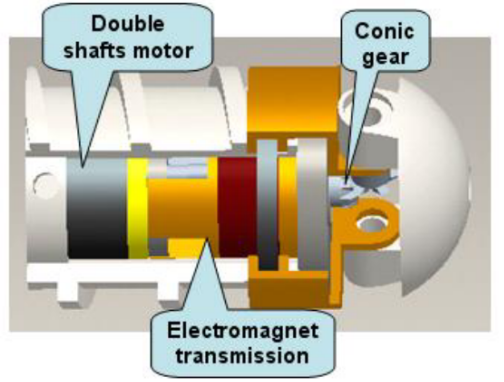

Fig. 16: Swimming robotic capsule endoscopy (Reprinted with permission. Copyright 2009, IEEE [60])

A locomotion system that combines hydrodynamic force and friction force was introduced by Liang et al. [15]. As shown in Fig. 17, a DC motor as the actuator drives a screw impeller to rotate, just as the mucus within GI tract pushing against the capsule to move forward based on the hydrodynamic force based mechanism. However, they also considered direct contact which includes the contact between capsule and the intestinal wall combining with the chyme. In this case, the screw impeller pushes against the intestinal wall and chyme instead of mucus, and advances linearly due to the friction force (the mixture of food and intestinal wall act as a stationary nut to transform the rotational motion of screw impeller into linear motion). A propeller based capsule endoscopy is also proposed by Tortora et al. [61], [62], which navigate within the stomach like a submarine (Fig. 18).

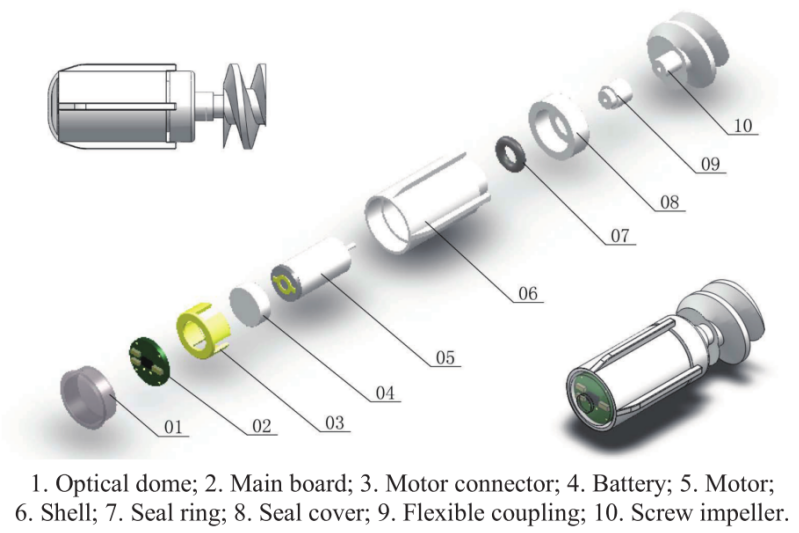

Fig. 17: Prototype of screw impeller capsule endoscopy (Reprinted with permission. Copyright 2011, IEEE [15])

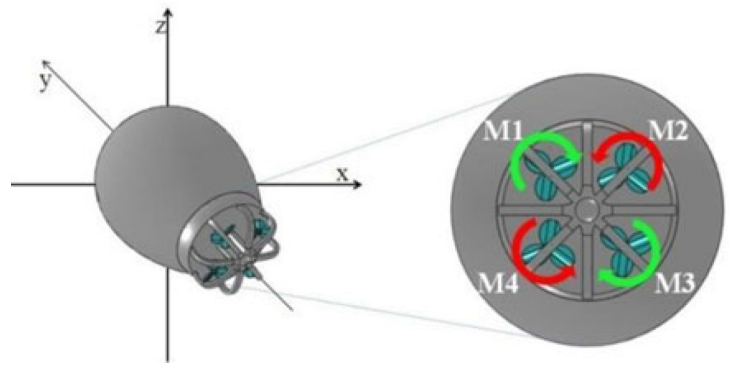

Fig. 18: Diagram of the propeller based capsule endoscopy (Reprinted with permission. Copyright 2013, IEEE [62])

\section{Summary}

Comparison of hydrodynamic locomotion systems is presented in the Tab. III; the power consumption of each prototype is as same as the paddle based system because both of them apply the DC motors as their actuators. According to Tab. III, hydrodynamic force based mechanism allows extremely high velocity in both directions. However, because of the spiral shape of the outer body, intraluminal tissue may easily get hurt when the capsule spins with high rotational velocity. High velocity (larger than $15 \mathrm{~cm} / \mathrm{min}$ ) may not allow enough time to picture abnormalities. In addition, like the 
paddle based and crawler mobility mechanism, this type of locomotion method cannot stop at a chosen position for clinical purposes.

3) Vibration Based Method: Vibration based mechanism is another method to drive the capsule endoscopy. An active capsule endoscopy was proposed by Carta et al. [63], which is driven by a vibratory motor using multi-coil inductive powering system. As shown in Fig. 19, the vibratory motor is simplified as an eccentric mass $m$, which rotates around the counter clockwise with a constant radius $r$ and an angular velocity $\omega$. When the vibratory motor starts to spin, the mass $m$ will create a centripetal force which can overcome the gravity and friction force acted on the capsule endoscopy to drive the whole body to navigate forward. This locomotion mechanism requires a minimum value of angular velocity to overcome frictional force. The threshold value of the angular velocity was near $2000 \mathrm{rpm}$ for the specific prototype described above. Considering that vibration based capsule endoscopy exploits the DC motor as its actuator, the power consumption should be similar to paddle based capsule endoscopy. The main strength of this prototype is ease of assembly and simplicity of locomotive mechanism. It is also less invasive than other locomotion methods. However, it is incapable to anchor and sometimes motion instability limits its clinical application.

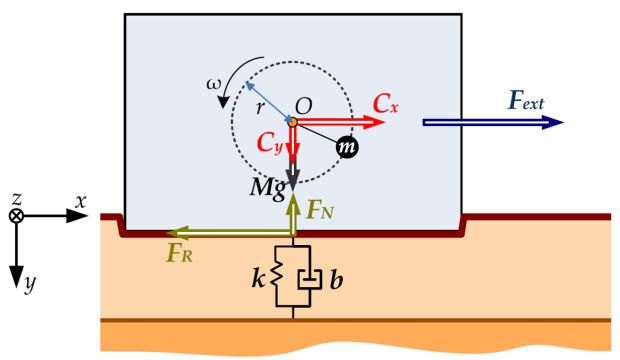

Fig. 19: Vibration based capsule endoscopy (Reprinted with permission. Copyright 2014, IEEE [64])

A vibratory motor has been exploited as a device for the reduction of contacted friction force between the capsule endoscopy and the intraluminal area. Zabulis et al. [65] and Ciuti et al. [66] presented a capsule endoscopy prototype embedded with an eccentric micro-motor for such purpose. Zabulis et al. verified the ability of the vibration based mechanism in friction reduction via several in-vitro tests. Ciuti et al. reported a $31 \%$ reduction of the friction force along the small intestine tissue and a $18 \%$ reduction along the large intestine tissue based on an ex vivo test. The reason why the vibration motility can decrease the friction force is the effect of in-plane vibrations, as described in detail in references [67]-[70].

\section{External Locomotion Method}

External method generally takes advantage of an external magnetic field (initiated by electromagnetic coils or permanent magnets) to propel the capsule endoscopy. By embedding one or more internal magnets on the capsular body and applying an external magnetic field, endoscopists can manipulate the capsule to accomplish the diagnostic task. Typically, external locomotion mechanisms are subdivided into two specific methods: rotational magnetic field method and magnetic platform method.

1) Rotational Magnetic Field Method: Sendoh et al. [71] and Hong et al. [72] designed an active capsule endoscopy propelled by external rotational magnetic field respectively. The method designed by Sendoh et al. [71] is similar to the hydrodynamic force based method but it concentrates on the external magnetic actuator instead of the micro-motor (Fig. 20). A permanent magnet is embedded on the capsule endoscopy when the magnetic field (initiated by three pairs of coils) starts to rotate. When the capsule body starts to rotate simultaneously due to the magnetism, the spiral structure pushes mucus backwards to drive the capsule endoscopy forward due to reaction force. This capsule endoscopy can change its moving direction by simply changing the rotational plane of the field. The velocity based on an in-vitro test (in tube) is over $1200 \mathrm{~mm} / \mathrm{min}$, and the dimension is $40 \mathrm{~mm}$ in length and $11 \mathrm{~mm}$ in diameter. The strengths and weaknesses are similar to the hydrodynamic force based capsule, but the power consumption inside the capsule is zero for this locomotion method, which avoids heat generation inside the GI tract.

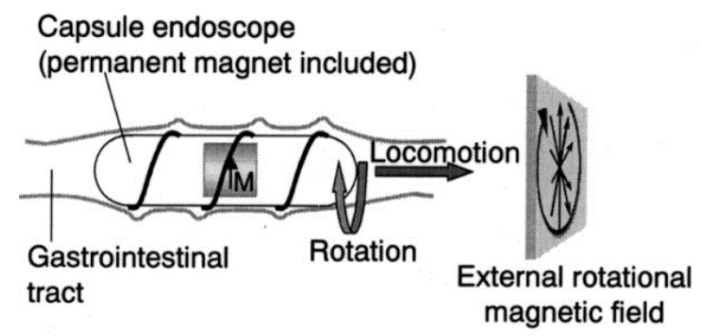

Fig. 20: Diagram of external locomotion method: rotational magnetic field (Reprinted with permission. Copyright 2003, IEEE [71])

2) Magnetic Platform Method: The magnetic platform method is much more mature than other methods because it can be precisely controlled and easily operated. In general, this method requires several external magnets or coils to generate magnetic field changes in multi-DOFs to drive the capsule endoscopy to perform precise motions. The control system basically consists of a human machine interface, a magnetic field controller (a console or robotic arm) with a joystick, and a locating device (MRI or CT machine).

Several research groups have studied this specific method [73]-[79]. Gao et al. [73] proposed a magnetic propulsion system that consists of a patient support, a magnet assembly and a magnet support as shown in Fig. 21 . These three components provide four DOFs (moving along the lateral or longitudinal direction and rotating about its vertical or longitudinal axis) for the capsule endoscopy to navigate inside the GI tract. A location control mode that inputs pulse signal 
TABLE III: Summary of Hydrodynamic force based capsule endoscopies

\begin{tabular}{|c|c|c|c|c|}
\hline Group & Prototype & Actuator & Size & Velocity(in tube) \\
\hline Liang et al. [15] & & Micro-motor & $\phi 12 \times 29 \mathrm{~mm}$ & $3600 \mathrm{~mm} / \mathrm{min}$ \\
\hline Chen et al. [60] & & Micro-motor & Design: $\phi 10 \times 40 \mathrm{~mm}$ & $600 \mathrm{~mm} / \mathrm{min}$ \\
\hline
\end{tabular}

is integrated into the human machine interface to guide the capsule to move accurately. The size of this capsule endoscopy is $34 \mathrm{~mm}$ in length and $12 \mathrm{~mm}$ in diameter without the magnetic shell, and the velocity is about $645 \mathrm{~mm} / \mathrm{min}$.

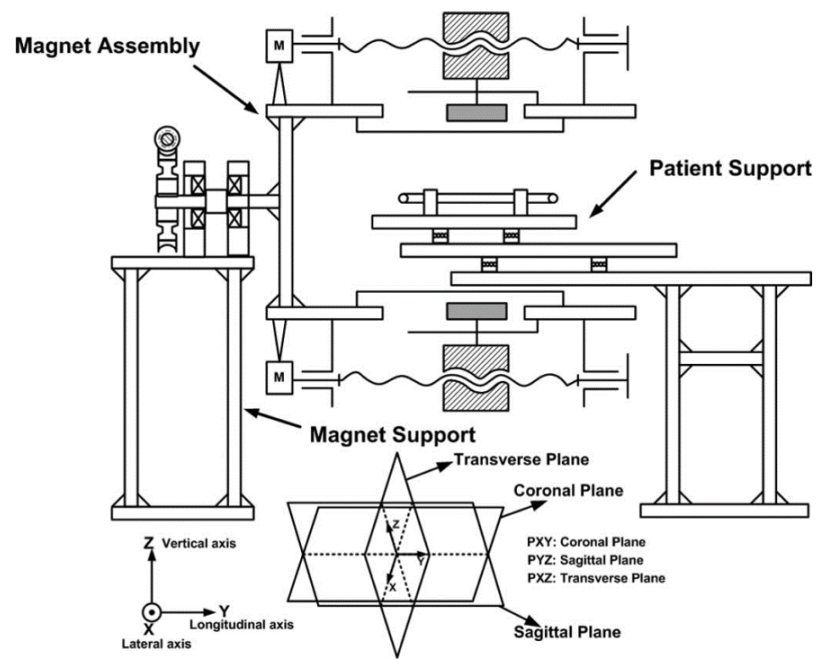

Fig. 21: Diagram of the magnetic propulsion system (Reprinted with permission. Copyright 2010, IEEE [73])

Another magnetic platform based method was presented by CRIM Lab [74]. The control system consists of a human machine interface, a robotic arm and a capsule device. The most important part of this system is the six DOFs industrial robotic arm with a permanent magnet at the tip. By assembling the whole system, they found the optimum working distance between the capsule endoscopy and the external permanent magnet is $150 \mathrm{~mm}$, and the related attraction force is about $315 \mathrm{mN}$. The diameter of the capsule is $18 \mathrm{~mm}$ and the length is $40 \mathrm{~mm}$. The average velocity is about $5 \mathrm{~cm} / \mathrm{min}$, which is slower than desired velocity of $15 \mathrm{~cm} / \mathrm{min}$.

The main drawback of the external magnetic navigation is the strong force applied on the body tissue from the attractive magnetic force. In order to address this issue, Yim et al. [75], [76] designed a compliant structure for the outer surface of the capsule endoscopy (Fig. 22). In this way, the capsule endoscopy is less invasive to the stomach and contracts along axial direction due to the magnetic force in order to fulfil several diagnostic purposes, such as drug delivery or biopsy in the future. When it comes to the manipulative method, the control system is composed of a rotating patient bed, a motorized stage combined with an external magnet which is controlled by a joystick, and a human machine interface. A rolling movement is introduced as follows: when the external magnet rotates, the capsule endoscopy starts to rotate simultaneously, in the meantime, one end of the capsule surface keeps anchor on the gastric wall due to the attraction force. Therefore, the capsule can navigate the whole stomach.
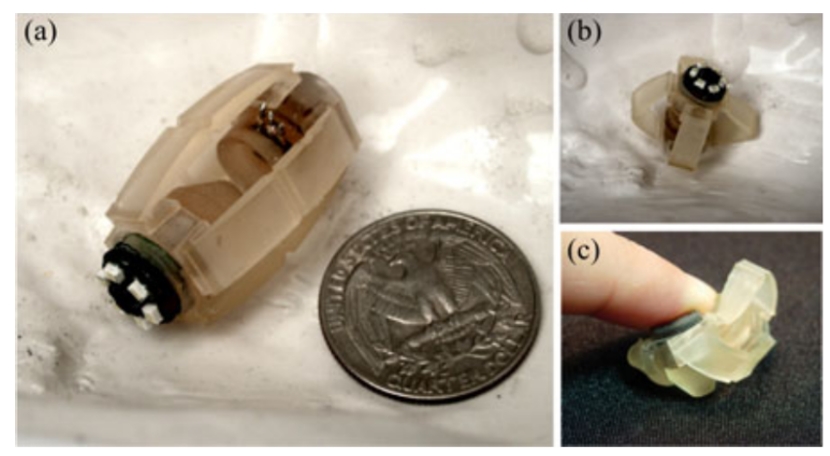

Fig. 22: Soft capsule endoscopy (Reprinted with permission. Copyright 2011, IEEE [75])

\section{Summary}

Tab. IV makes a comparison among the different external locomotion methods. The significant strength of the external locomotion method is no or less power consumption for the locomotion system inside the body, therefore the spatial potential due to the absence of battery or power support system, as well as the absence of internal locomotion system, can be utilized for other diagnostic consideration. Another advantage of external method is its precisely controlling and positioning technology. However, the external navigation system is very costly, and tissue damage is a possible complication due to the magnetic attraction. 
TABLE IV: Summary of external locomotion capsule endoscopies

\begin{tabular}{|c|c|c|c|c|c|}
\hline Group & Specific method & External actuator & Size & Velocity & $\begin{array}{c}\text { Monitor } \\
\text { area }\end{array}$ \\
\hline $\begin{array}{c}\text { Sendoh et al. } \\
{[71]}\end{array}$ & $\begin{array}{l}\text { Rotational magnetic } \\
\text { field method }\end{array}$ & $\begin{array}{l}\text { Three pairs of } \\
\text { coils }\end{array}$ & $\phi 11 \times 40 \mathrm{~mm}$ & $1200 \mathrm{~mm} / \mathrm{min}$ & Intestine \\
\hline Gao et al. [73] & $\begin{array}{c}\text { Magnetic } \\
\text { propulsion system } \\
\text { method }\end{array}$ & $\begin{array}{l}\text { Permanent } \\
\text { magnets }\end{array}$ & $\phi 12 \times 34 \mathrm{~mm}$ & $645 \mathrm{~mm} / \mathrm{min}$ & Intestine \\
\hline CRIM Lab [74] & $\begin{array}{l}\text { Robotic arm system } \\
\text { method }\end{array}$ & Permanent magnet & $\phi 18 \times 40 \mathrm{~mm}$ & $50 \mathrm{~mm} / \mathrm{min}$ & Intestine \\
\hline Lien et al. [77] & $\begin{array}{l}\text { Hand-held external } \\
\text { controller method }\end{array}$ & Permanent magnet & $\phi 10 \times 22 \mathrm{~mm}$ & $\begin{array}{c}20.02-118.25 \mathrm{r} / \mathrm{min} \text { (rotation } \\
\text { speed) }\end{array}$ & Stomach \\
\hline
\end{tabular}

\section{Other Methods}

A hybrid locomotion system for capsule endoscopy was also designed by Simi et al. [80] that combined the internal locomotion with external locomotion method. An external magnetic field generated by a permanent magnet is chosen to be the main locomotion function for driving the capsule endoscopy while an additional legged locomotion system is embedded on the capsule to be an assistant locomotion function. When capsule retention occurs, the legged locomotion system is activated to deliver the capsule from the collapsed area.

Another approach to drive the capsule endoscopy is the electrical stimulus method. Yoon et al. [81]-[86] designed and fabricated a stimulus capsular endoscopy, which utilized smooth muscles as an actuator. This prototype consists of an embedded electrical stimulation system and an external controller. As shown in Fig. 23, four electrodes controlled by the external controller engender electrical stimuli to lead the contraction of smooth muscle of the gastrointestinal tract. By taking advantage of this contraction, the capsule advances along the opposite direction. The moving direction and the

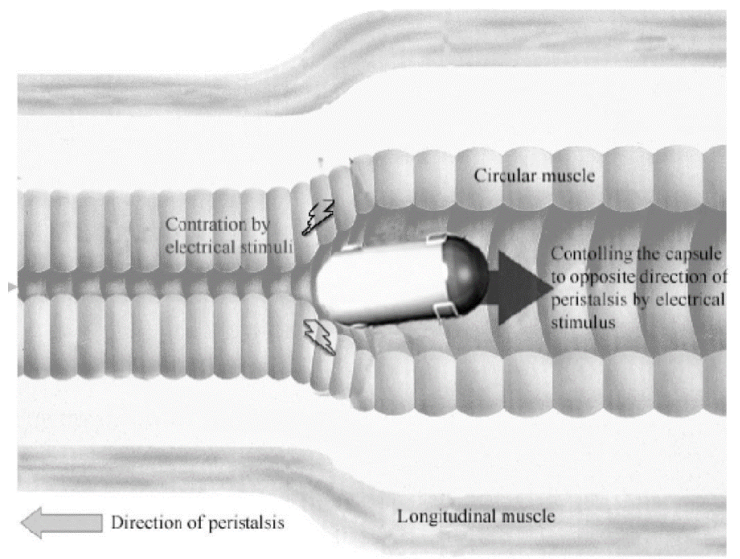

Fig. 23: Electrical stimulus method (Reprinted with permission. Copyright 2005, IEEE [81])

velocity are controlled by the external controller, and the maximum velocity is about $180 \mathrm{~mm} / \mathrm{min}$. The length and diameter of this prototype are $30 \mathrm{~mm}$ and $12 \mathrm{~mm}$ respectively.
Drawbacks of this locomotion system include control difficulty and possible body system disorders. The body system disorder could be liver function disturbance due to persistent stimulation of muscular or peristalsis motility perturbation [82].

\section{CONCLUSION AND FUTURE CAPSULE ENDOSCOPY}

Active locomotion systems for capsule endoscopy are reviewed and categorized along with advantages and disadvantages of each method (Tab. V). Fundamental properties of capsule endoscopes are described and comparisons are made for each locomotion system category. Fig. 24 shows a comparative plot of power consumption and velocity of different categories of locomotion methods. The asterisk, * indicates that the power consumption was not given. The black solid markers mean the locomotion method has the ability to stop for diagnostic purposes, and the empty markers mean it cannot stop. Ability to stop is an important feature for active capsule endoscopes. The desired velocity of $15 \mathrm{~cm} / \mathrm{min}$ is shown in the figure with a dotted line as a criterion to compare with the speed of different mechanisms. In addition, the power requirement needs to be minimized to be able to use the battery or the energy support system for a longer time. Authors hope this summary can provide a useful overview of current capsule endoscopy locomotion technology and can enlighten researchers to design capsule endoscopies that can overcome current limitations.

An efficient locomotion system should address the following aspects. First, it should consume low power, especially for the internal locomotion method because high power consumption requires additional power support system, and large size. Second, it should apply proper velocity in the range of $15 \mathrm{~cm} / \mathrm{min}$ because proper velocity guarantees the capsule endoscopy to accomplish the diagnostic purpose (slow velocity causes extra power consumption and wastes time, and high velocity may cause tissue damage). Third, it should have practical ability, such as the abilities of moving forwards, backwards, stopping and real-time control. Finally, it should be safe for GI tract tissue in terms of physical contact and temperature. In addition, future capsule endoscope should be able to to perform therapeutic functions, such as biopsy tissues, unclogging lumen, coagulating, ablating and apposing tissue [87]. 
TABLE V: Evaluations of locomotion systems

\begin{tabular}{|c|c|c|}
\hline Type of Mechanism & Advantages & Disadvantages \\
\hline Inchworm-like & Easy moving and stopping mechanism & High power consumption, low velocity, high temperature \\
\hline Crawler Mobility & High velocity, low power consumption & Inability to reverse and stop \\
\hline Paddle based & High velocity & $\begin{array}{l}\text { Inability to reverse and stop, inevitable risk of tissue damage } \\
\text { and capsule retention }\end{array}$ \\
\hline $\begin{array}{l}\text { Hydrodynamic force } \\
\text { based }\end{array}$ & High velocity in both directions & $\begin{array}{l}\text { Inability to stop, inevitable risk of tissue damage, liquid } \\
\text { environment limitation }\end{array}$ \\
\hline Vibration based & Non-invasive assembly, ease of application & Possible instability, inability to stop \\
\hline $\begin{array}{l}\text { Rotational magnetic field } \\
\text { method }\end{array}$ & $\begin{array}{l}\text { High velocity in both directions, no power consumption for } \\
\text { the locomotion system inside the capsule, spatial potential }\end{array}$ & $\begin{array}{c}\text { Inability to stop, inevitable risk of tissue damage, liquid } \\
\text { environment limitation }\end{array}$ \\
\hline $\begin{array}{l}\text { Magnetic platform } \\
\text { method }\end{array}$ & $\begin{array}{l}\text { No power consumption for the locomotion system inside the } \\
\text { capsule, spatial potential, precisely controlling and positioning }\end{array}$ & $\begin{array}{c}\text { High cost of navigation system, bulky equipment, possible risk } \\
\text { of tissue damage }\end{array}$ \\
\hline $\begin{array}{l}\text { Electrical stimulus } \\
\text { method }\end{array}$ & Simplest mechanism, least power consumption & Control difficulty, possible complication of digestive disorder \\
\hline
\end{tabular}

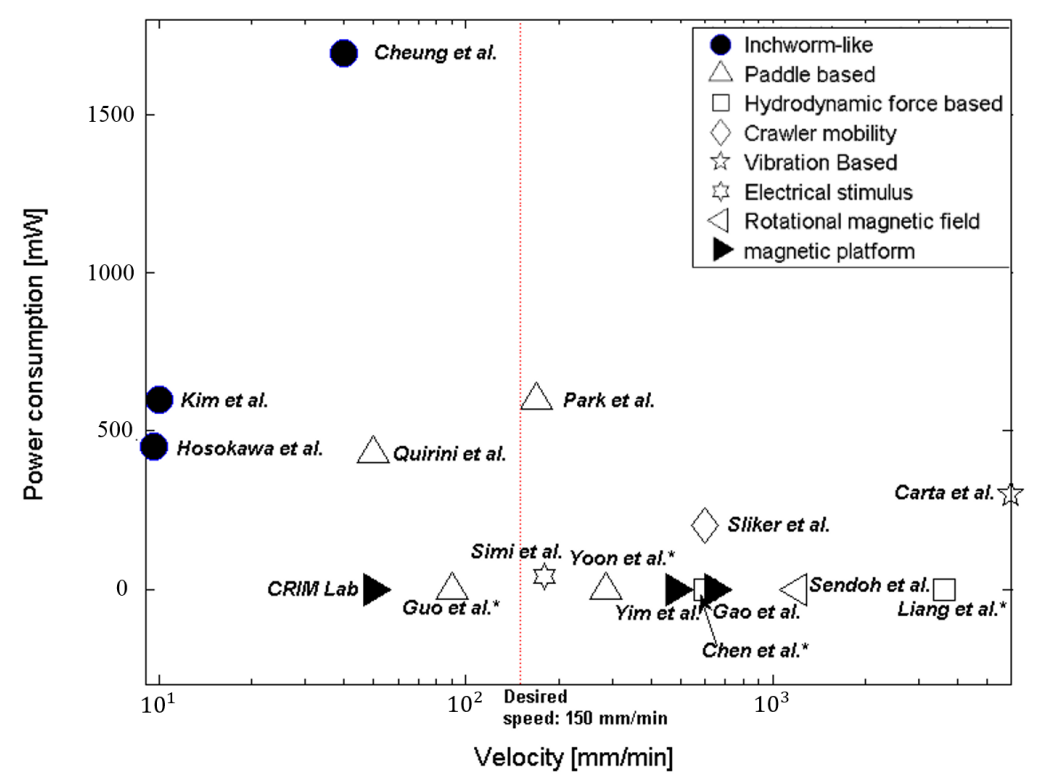

Fig. 24: Comparison of active locomotion systems

\section{REFERENCES}

[1] P. Swain, "Wireless capsule endoscopy and Crohn's disease." Gut, vol. 54, no. 3, pp. 323-6, Mar. 2005.

[2] C. a. Burke, J. Santisi, J. Church, and G. Levinthal, "The utility of capsule endoscopy small bowel surveillance in patients with polyposis." The American journal of gastroenterology, vol. 100, no. 7, pp. 1498502, Jul. 2005.

[3] A. Culliford, J. Daly, B. Diamond, M. Rubin, and P. H. R. Green, "The value of wireless capsule endoscopy in patients with complicated celiac disease." Gastrointestinal endoscopy, vol. 62, no. 1, pp. 55-61, Jul. 2005

[4] L. a. Ries, P. a. Wingo, D. S. Miller, H. L. Howe, H. K. Weir, H. M. Rosenberg, S. W. Vernon, K. Cronin, and B. K. Edwards, "The annual report to the nation on the status of cancer, 1973-1997, with a special section on colorectal cancer." Cancer, vol. 88, no. 10, pp. 2398-424, May 2000.

[5] A. Moglia, A. Menciassi, M. O. Schurr, and P. Dario, "Wireless capsule endoscopy: from diagnostic devices to multipurpose robotic systems." Biomedical microdevices, vol. 9, no. 2, pp. 235-43, Apr. 2007.
[6] A. Menciassi, M. Quirini, and P. Dario, "Microrobotics for future gastrointestinal endoscopy." Minimally invasive therapy \& allied technologies : MITAT : official journal of the Society for Minimally Invasive Therapy, vol. 16, no. 2, pp. 91-100, Jan. 2007.

[7] G. Ciuti, A. Menciassi, and P. Dario, "Capsule endoscopy: from current achievements to open challenges." IEEE reviews in biomedical engineering, vol. 4, pp. 59-72, Jan. 2011.

[8] A. Moglia, A. Menciassi, and P. Dario, "Recent Patents on Wireless Capsule Endoscopy," Recent Patents on Biomedical Engineeringe, vol. 1, no. 1, pp. 24-33, Jan. 2008.

[9] C. Gheorghe, R. Iacob, and I. Bancila, "Olympus capsule endoscopy for small bowel examination." Journal of gastrointestinal and liver diseases : JGLD, vol. 16, no. 3, pp. 309-13, Sep. 2007.

[10] S. Bang, J. Y. Park, S. Jeong, Y. H. Kim, H. B. Shim, T. S. Kim, D. H. Lee, and S. Y. Song, "First clinical trial of the "MiRo" capsule endoscope by using a novel transmission technology: electric-field propagation." Gastrointestinal endoscopy, vol. 69, no. 2, pp. 253-9, Mar. 2009.

[11] Z. Liao, "Fields of applications, diagnostic yields and findings of OMOM capsule endoscopy in 2400 Chinese patients," World Journal 
of Gastroenterology, vol. 16, no. 21, p. 2669, 2010.

[12] A. Wang, S. Banerjee, B. a. Barth, Y. M. Bhat, S. Chauhan, K. T. Gottlieb, V. Konda, J. T. Maple, F. Murad, P. R. Pfau, D. K. Pleskow, U. D. Siddiqui, J. L. Tokar, and S. a. Rodriguez, "Wireless capsule endoscopy." Gastrointestinal endoscopy, vol. 78, no. 6, pp. 805-15, Dec. 2013.

[13] C. M. Höög, L.-A. k. Bark, J. Arkani, J. Gorsetman, O. Broström, and U. Sjöqvist, "Capsule retentions and incomplete capsule endoscopy examinations: an analysis of 2300 examinations." Gastroenterology research and practice, vol. 2012, p. 518718, Jan. 2012.

[14] P. Glass, E. Cheung, and M. Sitti, "A legged anchoring mechanism for capsule endoscopes using micropatterned adhesives." IEEE transactions on bio-medical engineering, vol. 55, no. 12, pp. 2759-67, Dec. 2008.

[15] H. Liang, Y. Guan, and Z. Xiao, "A screw propelling capsule robot," Information and Automation (ICIA), no. 2009, pp. 786-791, 2011.

[16] L. J. Sliker, J. A. Schoen, and M. E. Rentschler, "Preliminary in Vivo Capsule Crawler Mobility," in Proc. ASME Des. Eng. Tech. Conf., vol. 2, no. PARTS A AND B, 2010, pp. 135-144.

[17] B. Kim, M. G. Lee, Y. P. Lee, Y. Kim, and G. Lee, "An earthworm-like micro robot using shape memory alloy actuator," Sensors and Actuators A: Physical, vol. 125, no. 2, pp. 429-437, Jan. 2006.

[18] H. Park, S. Park, E. Yoon, and B. Kim, "Paddling based microrobot for capsule endoscopes," Robotics and Automation, 2007 IEEE International Conference, no. April, pp. 10-14, 2007.

[19] F. Carpi, S. Galbiati, and A. Carpi, "Controlled navigation of endoscopic capsules: concept and preliminary experimental investigations," Biomedical Engineering, IEEE Transactions on, vol. 54, no. 11, pp. 2028-2036, 2007.

[20] P. Valdastri, M. Simi, and R. J. Webster, "Advanced technologies for gastrointestinal endoscopy." Аnnual review of biomedical engineering, vol. 14, pp. 397-429, Jan. 2012.

[21] Y. Ye, U. Khan, N. Alsindi, R. Fu, and K. Pahlavan, "On the accuracy of rf positioning in multi-capsule endoscopy," in Personal Indoor and Mobile Radio Communications (PIMRC), 2011 IEEE 22nd International Symposium on. IEEE, 2011, p. 2173.

[22] B. S. Terry, A. C. Passernig, M. L. Hill, J. a. Schoen, and M. E. Rentschler, "Small intestine mucosal adhesivity to in vivo capsule robot materials." Journal of the mechanical behavior of biomedical materials, vol. 15, pp. 24-32, Nov. 2012

[23] M. E. Smith and D. G. Morton, The digestive system : basic science and clinical conditions. Edinburgh ; New York : Churchill Livingstone, 2010.

[24] P. Valdastri, R. J. Webster, C. Quaglia, M. Quirini, S. Member, A. Menciassi, and P. Dario, "A new mechanism for mesoscale legged locomotion in compliant tubular environments," Robotics, IEEE Transactions, vol. 25, no. 5, pp. 1047-1057, 2009.

[25] F. Vilarino, P. Spyridonos, F. Deiorio, J. Vitria, F. Azpiroz, and P. Radeva, "Intestinal motility assessment with video capsule endoscopy: automatic annotation of phasic intestinal contractions." IEEE transactions on medical imaging, vol. 29, no. 2, pp. 246-59, Feb. 2010.

[26] H. Vu, T. Echigo, R. Sagawa, K. Yagi, M. Shiba, K. Higuchi, T. Arakawa, and Y. Yagi, "Detection of contractions in adaptive transit time of the small bowel from wireless capsule endoscopy videos." Computers in biology and medicine, vol. 39, no. 1, pp. 16-26, Jan. 2009.

[27] H. W. Davenport, Physiology of the digestive tract: an introductory text. Chicago: Year Book Medical Publishers, 1961.

[28] S. Wakimoto, I. Kumagai, and K. Suzumori, "Development of large intestine endoscope changing its stiffness," in Robotics and Biomimetics (ROBIO), 2009 IEEE International Conference on. IEEE, 2009, p. 2320.

[29] J. Wors $\varnothing$ e, L. Fynne, T. Gregersen, V. Schlageter, L. a. Christensen, J. F. Dahlerup, N. J. M. Rijkhoff, S. r. Laurberg, and K. Krogh, "Gastric transit and small intestinal transit time and motility assessed by a magnet tracking system.” BMC gastroenterology, vol. 11, p. 145, Jan. 2011.

[30] S. H. A. Woo, Z. Mohy-Ud-Din, and J. H. Cho, "Telemetry capsule for measuring contractile motion in the small intestine." Biomedical microdevices, vol. 15, no. 1, pp. 63-72, Feb. 2013.

[31] W. Q. Zhang, G. Z. Yan, D. D. Ye, and C. W. Chen, "Simultaneous assessment of the intraluminal pressure and transit time of the colon using a telemetry technique," Physiological Measurement, vol. 28, no. 2, p. 141, 2007.

[32] N.-K. Baek, I.-H. Sung, and D.-E. Kim, "Frictional resistance characteristics of a capsule inside the intestine for microendoscope design," Proceedings of the Institution of Mechanical Engineers, Part H: Journal of Engineering in Medicine, vol. 218, no. 3, pp. 193-201, Jan. 2004.

[33] J.-S. Kim, I.-H. Sung, Y.-T. Kim, E.-Y. Kwon, D.-E. Kim, and Y. H. Jang, "Experimental investigation of frictional and viscoelastic properties of intestine for microendoscope application," Tribology Letters, vol. 22, no. 2, pp. 143-149, Jun. 2006.

[34] X. Wang and M. Q.-H. Meng, "An experimental study of resistant properties of the small intestine for an active capsule endoscope," Proceedings of the Institution of Mechanical Engineers, Part H: Journal of Engineering in Medicine, vol. 224, no. 1, pp. 107-118, Jan. 2010.

[35] J. S. Kim, I. H. Sung, Y. T. Kim, S. E. Kim, and Y. H. Jang, "Analytical model development for the prediction of the frictional resistance of a capsule endoscope inside an intestine," Proceedings of the Institution of Mechanical Engineers, Part H: Journal of Engineering in Medicine, vol. 221, no. 8, pp. 837-845, Jan. 2007.

[36] E. Cheung, M. Karagozler, and M. Sitti, "A new endoscopic microcapsule robot using beetle inspired microfibrillar adhesives," Proceedings, 2005 IEEE/ASME International Conference on Advanced Intelligent Mechatronics., pp. 551-557, 2005.

[37] M. E. Karagozler, E. Cheung, J. Kwon, and M. Sitti, "Miniature endoscopic capsule robot using biomimetic micro-patterned adhesives," in Biomedical Robotics and Biomechatronics, 2006. BioRob 2006. The First IEEE/RAS-EMBS International Conference on. IEEE, 2006, pp. 105-111.

[38] D. Hosokawa and T. Ishikawa, "Development of a biologically inspired locomotion system for a capsule endoscope," The International Journal (Medical Robotics and Computer Assisted Surgery), no. September, pp. 471-478, 2009.

[39] D. Hosokawa, T. Ishikawa, and H. Morikawa, "A Locomotive System Mimicking Pedal Locomotion of Snails for the Capsule Endoscope," 4th European Conference of the International Federation for Medical and Biological Engineering, pp. 1655-1659, 2009.

[40] B. Kim, S. Park, and J.-O. Park, "Microrobots for a capsule endoscope," 2009 IEEE/ASME International Conference on Advanced Intelligent Mechatronics, pp. 729-734, Jul. 2009.

[41] J. Kwon, S. Park, J. Park, and B. Kim, "Evaluation of the critical stroke of an earthworm-like robot for capsule endoscopes," Proceedings of the Institution of Mechanical Engineers, Part H: Journal of Engineering in Medicine, vol. 221, no. 4, pp. 397-405, 2007.

[42] B. Kim, S. Park, and G. C. Y. Jee, "An earthworm-like locomotive mechanism for capsule endoscopes," 2005 IEEE/RSJ International Conference on Intelligent Robots and Systems, pp. 2997-3002, 2005.

[43] B. Kim, S. Lee, J. Park, and J.-O. Park, "Design and Fabrication of a Locomotive Mechanism for Capsule-Type Endoscopes Using Shape Memory Alloys (SMAs)," IEEE/ASME Transactions on Mechatronics, vol. 10, no. 1, pp. 77-86, Feb. 2005.

[44] R. Bogue, "Shape-memory materials: a review of technology and applications," Assembly Automation, vol. 29, no. 3, pp. 214-219, 2009.

[45] D. Mantovani, "Shape memory alloys: Properties and biomedical applications," JOM, no. October, 2000.

[46] M. Thrasher and A. Shahin, "Efficiency analysis of shape memory alloy actuators," Smart Materials and Structures, vol. 226, 1994.

[47] L. Schetky, "Engineering applications for shape memory alloys Present status, future potential," in Proceedings of the 1996 International 
Conference on Displacive Phase Transformations and their Applications in Materials Engineering. Minerals, Metals \& Materials Soc (TMS), 1998, pp. 149-156.

[48] H. Jia, F. Lalande, and C. Rogers, "Review of constitutive modeling of shape memory alloys." in Proceedings of the 1996 ASME International Mechanical Engineering Congress and Exposition, Atlanta, GA, USA, 1996, pp. 585-591.

[49] W. Tang and R. Sandstrom, "Property database on shape memory alloys for engineering design." Gaithersburg, MD, USA: ASTM, Philadelphia, PA, United States, 1995, pp. 85-95.

[50] Q. Shao, H. Liu, G. Li, X. Fang, and H. Li, "Thermal analysis of the internal force-static friction capsule robot," 2011 IEEE International Conference on Robotics and Biomimetics, pp. 414-418, Dec. 2011.

[51] R. Lu, S. Liu, X. Luo, and B. Zhang, "Thermal Safety Analysis of Capsule Endoscope," Electronic Packaging Technology, 2006. ICEPT '06. 7th International Conference, pp. 1-4, 2006.

[52] H. M. Kim, S. Yang, J. Kim, S. Park, J. H. Cho, J. Y. Park, T. S. Kim, E.-S. Yoon, S. Y. Song, and S. Bang, "Active locomotion of a paddlingbased capsule endoscope in an in vitro and in vivo experiment (with videos)." Gastrointestinal endoscopy, vol. 72, no. 2, pp. 381-7, Aug. 2010.

[53] S. Yang, K. Park, J. Kim, T. S. Kim, I.-J. Cho, and E.-S. Yoon, "Autonomous locomotion of capsule endoscope in gastrointestinal tract," in Engineering in Medicine and Biology Society, EMBC, 2011 Аnnиа International Conference of the IEEE. IEEE, 2011, pp. 6659-6663.

[54] E. Buselli, P. Valdastri, M. Quirini, A. Menciassi, and P. Dario, "Superelastic leg design optimization for an endoscopic capsule with active locomotion," Smart Materials and Structures, vol. 18, no. 1, p. 015001, Jan. 2009.

[55] M. Quirini and R. Webster, "Design of a pill-sized 12-legged endoscopic capsule robot," Robotics and Automation, 2007 IEEE International Conference, no. April, pp. 10-14, 2007.

[56] M. Quirini and A. Menciassi, "Design and fabrication of a motor legged capsule for the active exploration of the gastrointestinal tract," Mechatronics, IEEE/ASME Transactions, vol. 13, no. 2, pp. 169-179, 2008

[57] M. Quirini, A. Menciassi, S. Scapellato, P. Dario, F. Rieber, C.-N. Ho, S. Schostek, and M. O. Schurr, "Feasibility proof of a legged locomotion capsule for the GI tract." Gastrointestinal endoscopy, vol. 67, no. 7, pp. 1153-8, Jun. 2008

[58] W. Li, W. Guo, M. Li, and Y. Zhu, "Design and Test of a Capsule Type Endoscope Robot with Novel Locomation Principle," 2006 9th International Conference on Control, Automation, Robotics and Vision, pp. 1-6, 2006.

[59] L. Sliker, "Preliminary experimental results and modeling for a four degree of freedom automated traction measurement platform for quantitative evaluation of in vivo robotic capsule colonoscopy mobility,' Robotics and Automation (ICRA), 2013 IEEE International Conference, pp. 4875-4880, 2013.

[60] J. Chen, X. Zhu, and C. Qiu, "Locomotion and steering design of an active capsule robot for endoscopic inspection," 2009 IEEE International Conference on Robotics and Biomimetics (ROBIO), pp. 2344 2348, Dec. 2009

[61] R. Carta, G. Tortora, J. Thoné, B. Lenaerts, P. Valdastri, a. Menciassi, P. Dario, and R. Puers, "Wireless powering for a self-propelled and steerable endoscopic capsule for stomach inspection." Biosensors \& bioelectronics, vol. 25, no. 4, pp. 845-51, Dec. 2009.

[62] I. De Falco, G. Tortora, P. Dario, and A. Menciassi, "An integrated system for wireless capsule endoscopy in a liquid-distended stomach," Biomedical Engineering, IEEE Transactions on, vol. 61, no. 3, pp. 794 804, 2014.

[63] R. Carta, M. Sfakiotakis, N. Pateromichelakis, J. Thoné, D. Tsakiris, and R. Puers, "A multi-coil inductive powering system for an endoscopic capsule with vibratory actuation," Sensors and Actuators A: Physical, vol. 172, no. 1, pp. 253-258, Dec. 2011.
[64] M. Sfakiotakis, N. Pateromichelakis, and D. P. Tsakiris, "Vibrationinduced frictional reduction in miniature intracorporeal robots," Robotics, IEEE Transactions on, vol. 30, no. 5, pp. 1210-1221, 2014.

[65] X. Zabulis, M. Sfakiotakis, and D.-I. P. Tsakiris, "Effects of vibratory actuation on endoscopic capsule vision." Engineering in Medicine and Biology Society, 2008. EMBS 2008. 30th Annual International Conference of the IEEE, vol. 2008, pp. 5901-4, Jan. 2008.

[66] G. Ciuti, N. Pateromichelakis, M. Sfakiotakis, P. Valdastri, a. Menciassi, D. Tsakiris, and P. Dario, "A wireless module for vibratory motor control and inertial sensing in capsule endoscopy," Sensors and Actuators A: Physical, vol. 186, pp. 270-276, Oct. 2012.

[67] C. C. Tsai and C. H. Tseng, "The effect of friction reduction in the presence of in-plane vibrations," Archive of Applied Mechanics, vol. 75, no. 2-3, pp. 164-176, Dec. 2005.

[68] W. Littmann, H. Storck, and J. Wallaschek, "Sliding friction in the presence of ultrasonic oscillations: superposition of longitudinal oscillations," Archive of Applied Mechanics (Ingenieur Archiv), vol. 71, no. 8, pp. 549-554, Aug. 2001.

[69] H. Storck, W. Littmann, J. Wallaschek, and M. Mracek, "The effect of friction reduction in presence of ultrasonic vibrations and its relevance to travelling wave ultrasonic motors." Ultrasonics, vol. 40, no. 1-8, pp. 379-83, May 2002.

[70] P. Dahl, "Solid friction damping of mechanical vibrations." AIAA Journal, vol. 14, pp. 1675-82, 1976.

[71] M. Sendoh, K. Ishiyama, and K.-I. Arai, "Fabrication of magnetic actuator for use in a capsule endoscope," IEEE Transactions on Magnetics, vol. 39, no. 5, pp. 3232-3234, Sep. 2003

[72] Y.-S. Hong, J.-Y. Kim, Y.-C. Kwon, and S. Y. Song, "Preliminary study on capsule endoscopes propelled by variable threads." in 7th IASTED International Conference on Biomedical Engineering, BioMED 2010. Innsbruck, Austria: Acta Press, Building B6, Suite 101, 2509 Dieppe Avenue S.W., Calgary, AB, T3E 7J9, Canada, 2010, pp. 202-207.

[73] M. Gao, C. Hu, Z. Chen, H. Zhang, and S. Liu, "Design and fabrication of a magnetic propulsion system for self-propelled capsule endoscope." IEEE transactions on bio-medical engineering, vol. 57, no. 12, pp. 2891-902, Dec. 2010

[74] G. Ciuti, P. Valdastri, A. Menciassi, and P. Dario, "Robotic magnetic steering and locomotion of capsule endoscope for diagnostic and surgical endoluminal procedures," Robotica, vol. 28, no. 02, p. 199, Oct. 2009.

[75] S. Yim and M. Sitti, "Design and rolling locomotion of a magnetically actuated soft capsule endoscope," Robotics, IEEE Transactions on, vol. 28, no. 1, pp. 183-194, 2012.

[76] _ "Design and analysis of a magnetically actuated and compliant capsule endoscopic robot," 2011 IEEE International Conference on Robotics and Automation, pp. 4810-4815, May 2011.

[77] G.-S. Lien, C.-W. Liu, J.-A. Jiang, C.-L. Chuang, and M.-T. Teng, "Magnetic control system targeted for capsule endoscopic operations in the stomach-design, fabrication, and in vitro and ex vivo evaluations." IEEE transactions on bio-medical engineering, vol. 59, no. 7, pp. 206879, Jul. 2012.

[78] F. Carpi, N. Kastelein, M. Talcott, and C. Pappone, "Magnetically Controllable Gastrointestinal Steering of Video Capsules," vol. 58, no. 2, pp. 231-234, 2011.

[79] Uehara and Hoshina, "Capsule endoscope NORIKA system." Minimally invasive therapy \& allied technologies : MITAT : official journal of the Society for Minimally Invasive Therapy, vol. 12, no. 5, pp. 227-34, Sep. 2003.

[80] M. Simi, P. Valdastri, C. Quaglia, a. Menciassi, and P. Dario, "Design, Fabrication, and Testing of a Capsule With Hybrid Locomotion for Gastrointestinal Tract Exploration," IEEE/ASME Transactions on Mechatronics, vol. 15, no. 2, pp. 170-180, Apr. 2010.

[81] T. W. Kim, S. H. W. K. W. Yoon, J. H. Lee, Y. K. Moon, C. H. Won, H. C. Choi, and J. H. Cho, "Design and Implement the Stimuli Capsule at In-vitro Experiment," in IEEE Region 10 Annual International 
Conference, Proceedings/TENCON. Melbourne, Australia: Institute of Electrical and Electronics Engineers Inc., 445 Hoes Lane / P.O. Box 1331, Piscataway, NJ 08855-1331, United States, 2007.

[82] S. H. Woo, T. W. Kim, and J. H. Cho, "Stopping mechanism for capsule endoscope using electrical stimulus." Medical \& biological engineering \& computing, vol. 48, no. 1, pp. 97-102, Jan. 2010.

[83] H.-J. Park, J.-H. Lee, Y.-K. Moon, Y.-H. Yoon, C.-H. Won, H.-C. Choi, and J.-H. Cho, "New Method of Moving Control for Wireless Endoscopic Capsule Using Electrical Stimuli." Communications and Computer Sciences, vol. E88-A, no. 6, pp. 1476-80, 2005.

[84] Y. Moon, J. Lee, H. Park, J. Lee, J. Ryu, S. Woo, M. Kim, C. Won, T. Kim, J. Cho, and H. Choi, "Fabrication of the Wireless Systems for Controlling Movements of the Electrical Stimulus Capsule in the Small Intestines." IEICE Transactions on Information and Systems, vol. E90D, no. 2, pp. 586-592, 2007.

[85] C. a. Mosse, T. N. Mills, M. N. Appleyard, S. S. Kadirkamanathan, and C. P. Swain, "Electrical stimulation for propelling endoscopes." Gastrointestinal endoscopy, vol. 54, no. 1, pp. 79-83, Jul. 2001.

[86] S. H. Woo, T. W. Kim, Z. Mohy-Ud-Din, I. Y. Park, and J.-H. Cho, "Small intestinal model for electrically propelled capsule endoscopy." Biomedical engineering online, vol. 10, p. 108, Jan. 2011.

[87] D. E. Fleischer, "Motion in the direction of making the video capsule our primary endoscope." Gastrointestinal endoscopy, vol. 72, no. 2, pp. 388-91, Aug. 2010. 